\title{
From the Desk of the Indian Society of Vascular and Interventional Radiology
}

\author{
Arun Gupta ${ }^{1} \quad$ Vimal Someshwar \\ ${ }^{1}$ Department of Interventional Radiology, Sir Ganga Ram Hospital, \\ New Delhi, India \\ ${ }^{2}$ Department of Interventional Radiology, Kokilaben Dhirubhai \\ Ambani Hospital, Mumbai, Maharashtra, India \\ J Clin Interv Radiol ISVIR 2018;2:2-2
}

The Indian Society of Vascular and Interventional Radiology (ISVIR) had a very fruitful year during 2017-2018. Our society has grown with more than 600 members. The society organized many academic meetings and conferences during the year, which immensely allowed the members to collaborate and learn from each other. The 20th annual conference of the ISVIR that was held at the Sanjay Gandhi Postgraduate Institution, Lucknow, India, during February 2018 was a grand success. We congratulate and thank the organizing committee and the executive members for this achievement. It was very exciting to see many young enthusiastic interventional radiologists participate in the conference. The "complications meeting" was an opportunity to be aware of complications, learn from our mistakes, and bring in processes to minimize the complications in our practice. The presentations during the "complications meeting" were categorized to represent a larger spectrum of diseases treated by interventional radiologists. Our efforts to introduce DNB (Diplomate of National Board) and DM (Doctor of Medicine) courses in interventional radiology (IR) have intensified. The society is supportive of fellowship training programs in IR for young enthusiastic candidates.

A new executive committee of ISVIR has been selected during the annual conference. We are grateful to the invaluable contributions from the outgoing treasurer Dr. Rajesh Mundhada and secretary Dr. Suyash Kulkarni.

We congratulate and express heartfelt appreciation to all the authors, reviewers, and editors of the Journal of Clinical and Interventional Radiology (JCIR) on behalf of the executive body of the ISVIR. We specially thank Prof. Shyamkumar Keshava and Prof. Sanjeeva Kalva for their invaluable efforts and hard work in successfully bringing this

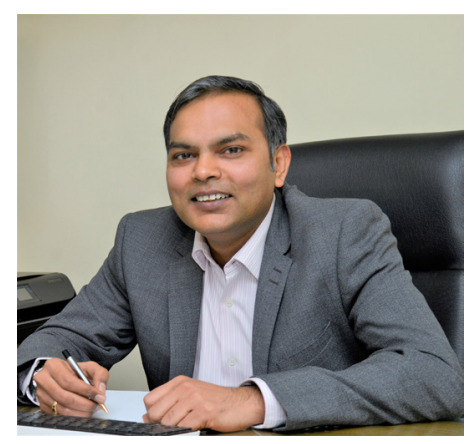

Arun Gupta, Secretary, ISVIR ${ }^{1}$

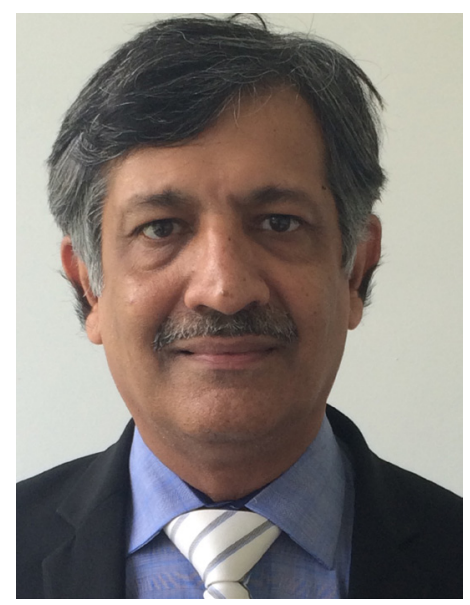

Vimal Someshwar, President, ISVIR ${ }^{2}$ journal to fruition. It was with the cooperation, enthusiasm, and spirit of the authors and reviewers that we could make JCIR a grand success. We appreciate the excellent support of Thieme Publishers in these efforts. The success of the journal is one of the testaments of the efforts of the society to bring international outreach of the great work occurring in India.

Working together and learning from each other are our strengths. Improving awareness and reaching out to other medical and surgical societies would be the direction for the coming year. Dedicated programs through our educational promotion wing (ISVIR-REF) will be planned to reach the postgraduate and undergraduate students in medical colleges. The society will support any academic activity that an individual interventional radiologist intends to undertake. The ISVIR is also actively interacting with international societies, including the Cardiovascular and Interventional Radiological Society of Europe (CIRSE), the Society of Interventional Radiology (SIR), and the Asia Pacific Society of Cardiovascular and Interventional Radiology (APSCVIR).

Let us all work together and play an important role in our patient care.

Address for correspondence: Arun Gupta, MBBS, MD, Secretary, Indian Society of Vascular and Interventional Radiology (ISVIR), Chairperson, Department of Interventional Radiology, Room No. 20A, Sir Ganga Ram Hospital, New Delhi 110060, India (e-mail: secretary@isvirindia.org).
DOI https://doi.org/

10.1055/s-0038-1649552. ISSN 2457-0214.
Copyright (c) 2018 by Indian Society of Vascular and Interventional Radiology
License terms

() (1) $\ominus \circledast$ 